\title{
Construction of Improved PCR Primer Set for the Detection of Human Enteric Adenovirus 41
}

\author{
Kyu-Bong Cho ${ }^{\dagger}$ ** \\ Department of Biomedical Laboratory Science, Shinhan University, Uijeongbu 11644, Korea
}

\begin{abstract}
Human enteric Adenovirus-41 (HuEAdV-41) causes gastroenteritis, which detected by the polymerase chain reaction (PCR) base diagnostic system for clinical, food, environmental, fish and shellfish samples. We developed improved PCR and nested PCR primer set which had high specificity, sensitivity and reduced times. In this study, we compared seventeen conditions reported in the previous study that was using the PCR based HuEAdV-41 detection system, and non-enteric Adenovirus were detected in nine conditions. The most sensitive detection condition was up to 25 copies however it took 184 minutes of PCR reaction time. In this study, the PCR primer set developed had same level of sensitivity, it reduced the time of detection for clinical, food and seafood samples to 112 minutes. Developed nested PCR primer set needed 112 minutes but detected up to approximately 1 copy. In addition, developed PCR and nested PCR primer set was validated with twenty samples of underground water at random, of which ten samples showed specific band without non-specific reaction. We expect this study will be used to diagnose HuEAdV-41 from various samples.
\end{abstract}

Key Words: Adenovirus-41, HuEAdV-41, Polymerase chain reaction, Nested PCR

\section{서 론}

사람 장아데노바이러스(Human Enteric Adenovirus; $\mathrm{HuEAdV}$ )는 group I의 dsDNA virus로써 아데노바이러스 과로 분류된다(Rowe et al., 1953). HuEAdV는 증상에 따라 subgroup A-G로 나뉘며, 위장염을 일으키는 그룹은 F와 $\mathrm{G}$ 로 이 중 $\mathrm{F}$ 형은 소장과 장내 생존 가능성이 보고되었다 (Uhnoo et al., 1984; Grimwood et al., 1995). 그룹 F형은 혈 청형 40과 41로 구성되며, 특히 소아 등 노약자에게 위 장염을 일으키는 주요 혈청형은 41형이다(Johansson et al., 1985). HuEAdV-41을 검출하기 위한 방법으로는 특이적 핵 산을 증폭하는 중합효소연쇄반응(polymerase chain reaction; $\mathrm{PCR})$ 이 주로 활용되고 있으며, 임상, 식품, 어패류, 환경
등에서 주로 사용되는 검사방법이다(Girones et al., 1995; Echavarria et al., 1998). 그러나 HuEAdV-41을 검출하기 위 한 진단 기술은 다수의 연구자들에 의해 개발되어 검사 조건이 모두 다르며, 특이도 및 검출 민감도 등 각각의 검사방법에 대한 비교 연구가 상대적으로 미흡한 실정이 다. 또한 다양한 시료들 중 지하수 등과 같은 비 소독수 처럼 극미량으로 오염된 바이러스를 검출할 수 있을 정도 의 검출감도가 필요하다. 따라서 이번 연구에서는 현재까 지 개발된 기존의 PCR 방법보다 HuEAdV-41을 높은 특 이도 및 민감도로 검출할 수 있는 PCR 및 nested PCR 프 라이머 조합을 개발하고자 본 연구를 수행하였다.

Received: August 17, 2018 / Revised: September 10, 2018 / Accepted: September 11, 2018

*Professor.

${ }^{\dagger}$ Corresponding author: Kyu-Bong Cho. Department of Biomedical Laboratory Science, Shinhan University, Uijeongbu 11644, Korea. Tel: +82-31-870-3712, Fax:+82-31-870-3719, e-mail: kbcho@shinhan.ac.kr

(C) The Korean Society for Biomedical Laboratory Sciences. All rights reserved.

@(c) This is an Open Access article distributed under the terms of the Creative Commons Attribution Non-Commercial License (http://creativecommons.org/licenses/by-nc/3.0/) which permits unrestricted non-commercial use, distribution, and reproduction in any medium, provided the original work is properly cited. 


\section{재료 및 방법}

\section{프라이머 설계}

$\mathrm{HuEAdV}$ 의 혈청형 결정 유전자 부위인 HuEAdV-41 hexon gene을 대상으로 특이적 프라이머를 설계하였다(Fig. 1). 민감도와 특이도를 검증하기 위하여 미국 국립생물정 보센터(National Center for Biotechnology Information)에서 Human Adenovirus 41 isolate Tak (AB610519.1)을 비롯한 20 개 참고 수인성·식품매개 바이러스 염기서열을 수집하 였다. 염기서열들은 BioEdit version 7.1.3을 사용(Hall, 1998) 하여 다중염기서열 정렬 후, DNAMAN software package version 6.0 (Lynnon Biosoft, Quebec, Canada)을 사용하여 annealing 조건 $51 \sim 59^{\circ} \mathrm{C}$ 범위에서 프라이머 종류에 따라 각각 $2^{\circ} \mathrm{C}$ 차이로 종 특이적인 염기서열을 탐색하였다. 탐 색한 특이적 프라이머들은 Oligo Calculator version 3.27을
사용하여 특성 확인 및 potential hairpin formation 등을 검 정하였다(Kibbe, 2007).

\section{바이러스 핵산 수집}

HuEAdV-41 프라이머 조합들의 특이성을 분석하기 위 하여 대상 바이러스인 HuEAdV-41 [AMPLIRUN ${ }^{\circledR}$ ADENOVIRUS 41 DNA CONTROL MBC001 (Vircell, Spain)]과 참고 바이러스 11종[Rotavirus A (RV-A), Parechovirus A (PechoV), Norovirus GII (NoV-GII), Coronavirus 229E (CorV-229E), Enterovirus 68, 71 (EV-68, 71), Coxsackievirus A6, B1, B5 (CoxV-A6, B1, B5), non-enteric Adenovirus (NeAdV) 및 Parvovirus B19(PaV-B19)]의 핵산을 수집하였다.

PCR 및 이 중 중합효소연쇄반응(nested PCR) 프라이머 선발

설계된 PCR 프라이머를 조합하여 증폭이 가능한 50 개

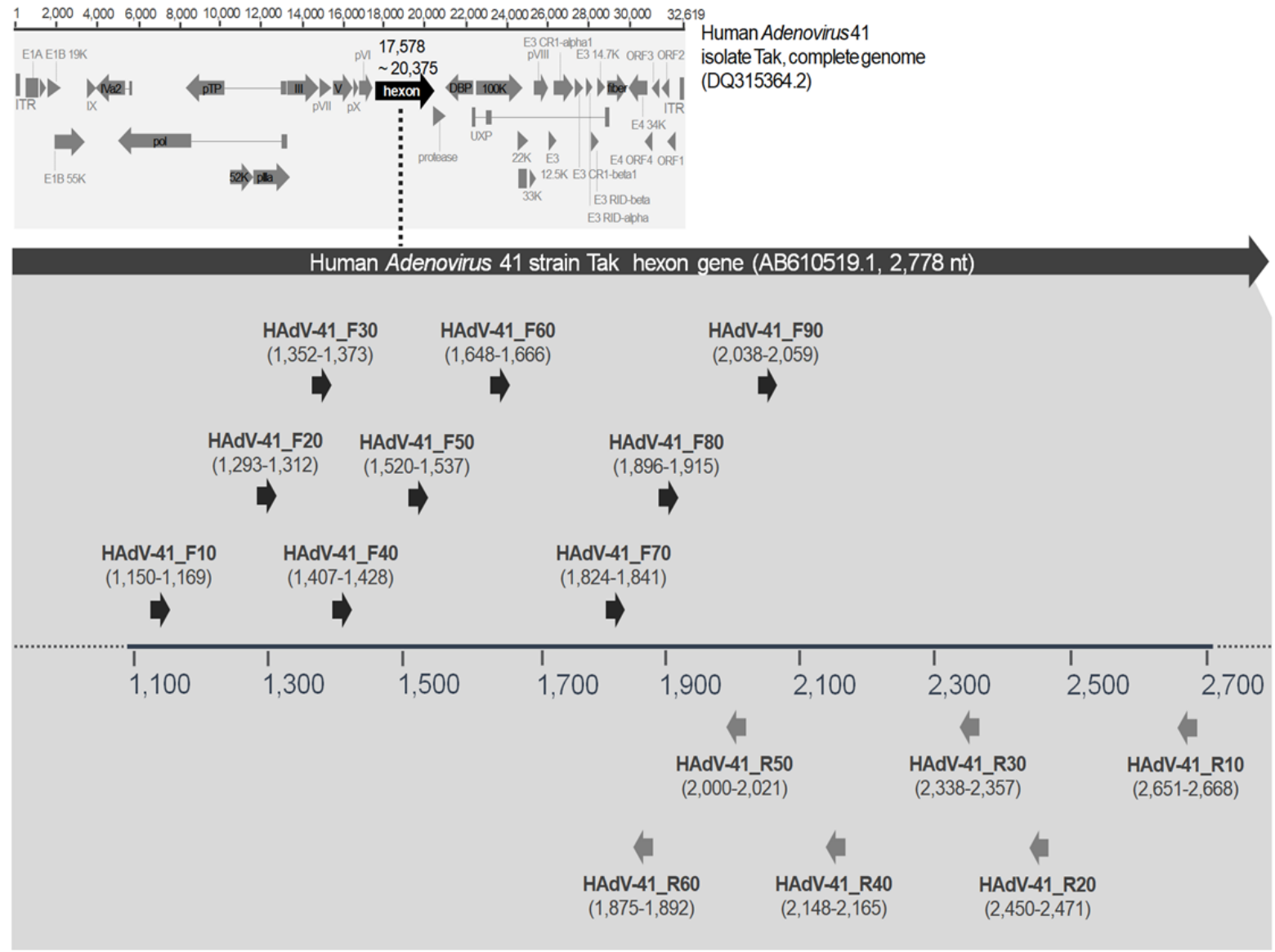

Fig. 1. Specific PCR primer map for the detection of human enteric Adenovirus 41 


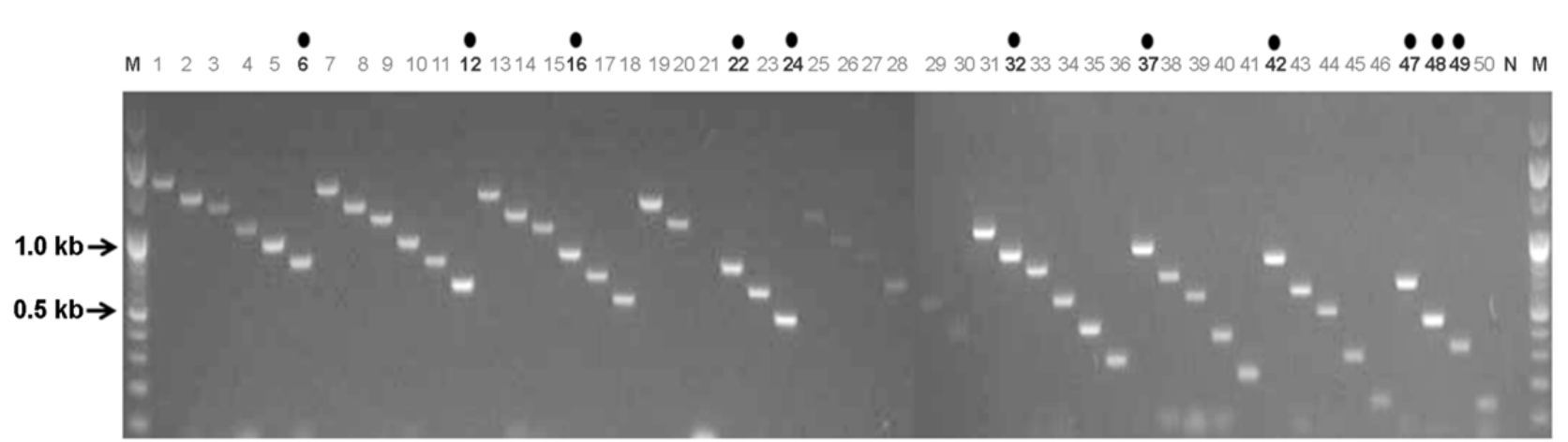

Fig. 2. Specific reaction of primer sets for detection of HEAdV-41. Lane M, 100 bp Ladder marker; lane number, primer sets number (1 50); $\mathrm{N}$, negative control; dot, selective primer sets.

조합을 구성하였다. 구성한 조합들을 대상으로 HuEAdV$41 \mathrm{DNA}$ 에 특이적으로 반응을 나타내고, 참고 바이러스 11 종의 핵산에 비 특이적으로 반응하는 프라이머 조합을 선발하였다. 이후 특이적 및 비 특이적 반응에서 선발한 프라이머 조합들을 대상으로 HuEAdV-41 DNA를 10배 계 단 희석한 후 주형과의 검출감도 비교를 통해 프라이머를 선발하였다. 또한, 극미량 오염된 시료 등에서도 활용이 가능하도록 nested PCR 프라이머 조합을 개발하였다. 검 출감도 시험에서 선발된 프라이머 조합을 이용하여 nested $\mathrm{PCR}$ 조합들을 설계한 후, 각 $\mathrm{PCR}$ 산물을 주형으로 검 출감도를 비교하였다. 한편, PCR 반응액은 AccuPower ${ }^{\circledR}$ HotStart PCR PreMix (Bioneer, Korea), 정방향 및 역방향 프 라이머 $(25 \mathrm{pmol})$ 각 $1 \mu \mathrm{L}$, 주형 DNA $1 \mu \mathrm{L}$ 및 nucleic acid free water $17 \mu \mathrm{L}$ 로 최종 $20 \mu \mathrm{L}$ 로 수행하였다. $\mathrm{PCR}$ 반응 온도 조건은 $95^{\circ} \mathrm{C}$ 에서 10 분 동안 초기 변성단계를 거쳐 $75^{\circ} \mathrm{C}$ 에서 45 초간 변성, $55^{\circ} \mathrm{C}$ 에서 1 분간 결합, $72^{\circ} \mathrm{C}$ 에서 1 분간 신장하는 단계를 35 회 반복하였으며 그 후 $72^{\circ} \mathrm{C}$ 에 서 5 분간 최종 신장하였다. PCR 산물들은 $1.2 \%$ agarose gel 에서 $100 \mathrm{~V}, 30$ 분간 전기영동 후 gel documentation system (BioRad, USA)에서 확인하였다.

\section{기존 시험법 비교}

HuEAdV-41의 특이 유전자를 증폭하는 PCR 및 nested $\mathrm{PCR}$ 은 17 개 조건이 검색되었으며, 이들 방법들의 반응시 간, 검출 민감도 및 특이도를 분석하였다. PCR 조건은 각 각의 참고문헌들과 동일하게 수행하였다(Allard et al., 1992; Flomengerg et al., 1995; Kidd et al., 1996; Akalu et al., 1998; Castignolles et al., 1998; Echavarría et al., 1998; Xu et al., 2000; Allard et al., 2001; Oh et al., 2003; Hansman et al., 2008; Tai,
2008; Kuo et al., 2009; KMFDS, 2013; Arcangeletti et al., 2014; Jang et al., 2017). 반응시간은 기존 방법들의 반응온도 조 건을 적용하였고, HuEAdV-41 DNA를 10배 계단 희석한 후 주형으로 검출 민감도를 확인하였으며, NeAdV DNA를 주형으로 특이도를 분석하였다.

\section{시료 적용성 시험 및 최종 선발}

HuEAdV-41 검출용 프라이머 조합들의 시료 적용성 시 험을 위하여 미량 오염 또는 음성이 예상되는 지하수 시 료를 무작위로 20 개 채취하였으며, 국립환경과학원 고시 제 2017-50호에 의거하여 지하수 시료는 탈리 및 농축을 수행하였다. 농축 시료는 DNeasy ${ }^{\circledR}$ PowerWater ${ }^{\circledR}$ Kit (Qiagen, Germany)를 사용하여 제품 매뉴얼에 따라 총 핵산(total $\mathrm{DNA})$ 을 추출하였다. 추출한 핵산을 주형으로 새로이 개 발한 프라이머 조합들과 기존 PCR 방법들 중 특이도 및 검출 민감도가 가장 높은 프라이머 조합을 대상으로 비교 하였다.

\section{결 과}

\section{$\mathrm{PCR}$ 프라이머 선발}

HuEAdV-41 유전자에 대한 특이적 반응에서 50개 조합 모두에서 126 1,519 bp의 특정 밴드가 형성되었으며 밴 드의 크기, 강도 및 위치를 고려하여 11 개 조합을 선발하 였다(Fig. 2). 선발된 11개 조합의 특이 프라이머를 이용하 여 참고 바이러스 11 종에 대하여 $\mathrm{PCR}$ 를 시행한 결과 모 든 조합에서 비 특이적 반응은 나타나지 않았다(Data not shown). HuEAdV-41 DNA를 100, 50, 25, 10, 5 및 1 copy로 희석하여 11 개 조합에 대한 검출 민감도를 분석한 결과, 
Table 1. Sensitive test of PCR and nested PCR primer sets for detection of HEAdV-41

\begin{tabular}{|c|c|c|c|c|c|}
\hline \multicolumn{3}{|c|}{ PCR primer set } & \multicolumn{3}{|c|}{ Nested PCR primer set } \\
\hline $\begin{array}{c}\text { Number } \\
\text { (forward/reverse primer) }\end{array}$ & $\begin{array}{l}\text { Length } \\
\text { (bp) }\end{array}$ & $\begin{array}{l}\text { Sensitivity } \\
\text { (copies) }\end{array}$ & $\begin{array}{l}\text { Number of } \\
\text { candidates }^{\text {a }}\end{array}$ & $\begin{array}{l}\text { Selective primer set } \\
\quad(\text { size, bp) }\end{array}$ & $\begin{array}{l}\text { Sensitivity } \\
\text { (copies) }\end{array}$ \\
\hline \#06(AdV41_F10/R60) & 743 & 25 & - & $\mathrm{ND}^{\mathrm{b}}$ & \\
\hline \#12 (AdV41_F20/R60) & 600 & 10 & 2 & AdV41_F40/R60 (486) & 1 \\
\hline \#16 (AdV41_F30/R40) & 814 & 50 & - & ND & \\
\hline \#22 (AdV41_F40/R40) & 759 & 10 & 5 & AdV41_F90/R30 (320) & 1 \\
\hline \#24 (AdV41_F40/R60) & 486 & 25 & - & ND & \\
\hline \#32 (AdV41_F60/R20) & 824 & 10 & 4 & AdV41_F90/R20 (434) & 1 \\
\hline \#37 (AdV41_F70/R10) & 845 & 100 & - & ND & \\
\hline \#41 (AdV41_F80/R10) & 773 & 10 & 3 & AdV41_F90/R20 (434) & 1 \\
\hline \#47 (AdV41_F90/R10) & 631 & 25 & 2 & AdV41_F90/R20 (434) & 1 \\
\hline \#48 (AdV41_F90/R20) & 434 & 50 & - & ND & \\
\hline \#49 (AdV41_F90/R30) & 320 & 100 & - & ND & \\
\hline
\end{tabular}

${ }^{\mathrm{a}}$ Number of nested PCR primer sets of selecteved PCR primer set; ${ }^{\mathrm{b}}$ No data.

상대적으로 높은 검출 민감도를 나타낸 조합은 6 개였다. 이 중 nested PCR 프라이머 선발을 고려하여 $600 \sim 850 \mathrm{bp}$ 를 증폭할 수 있는 5 개 조합(\#12, \#22, \#32, \#41 및 \#47)을 선발하였으며, 검출 민감도는 $10 \sim 25$ copies 수준이었다 (Table 1).

\section{Nested PCR 프라이머 선발}

1 차 PCR 검출 민감도 시험에서 선발된 5개 $\mathrm{PCR}$ 프라 이머 조합에 대한 nested PCR 프라이머 조합을 설계하였 다. 그 결과 조합 \#12(2개), \#22(5개), \#32(4개), \#41(3개) 및 \#47(2개)의 nested PCR 프라이머 조합이 각각 설계되었다. Nested PCR의 검출 민감도는 1 5 copies 수준이었으며, 밴드의 강도, 크기 등을 고려하여 각각의 $\mathrm{PCR}$ 프라이머 조합마다 1 개의 nested PCR 프라이머 조합을 최종 선발하 였다(Table 1).

\section{기존 시험법 비교}

HuEAdV-41의 특이적 핵산 증폭이 가능한 기존의 17 개 조건을 대상으로 검출 민감도, 특이도, 기타 비 특이적 증 폭, 반응시간을 분석하였다. 이 중 9 개 조합은 $\mathrm{NeAdV}$ 핵 산은 검출되었지만 특이도가 좋지 않았으며, 특이도가 좋 았던 8 개 조건 중, 6 개 조건은 100 copies 이상일 때 검출 되었고, 나머지 2개 조합은 각각 50과 25 copies 수준으로 검출되었다(Table 2). 그러나 가장 좋은 특이성 및 검출 민 감도를 가진 조합은 184 분의 PCR 반응이 필요하여 다른
조건들에 비해 반응시간이 길었다.

\section{시료 적용성 시험 및 최종 선발}

지하수에서 추출한 20 개 총 핵산을 사용하여 기존 시 험법에서 높은 특이성 및 검출 민감도를 보인 프라이머 조합 및 1 차 $\mathrm{PCR}$ 프라이머 5 개 조합(\#12,\#22, \#32,\#41 및 \#47)으로 PCR 반응을 수행한 결과, 기존 시험법 조건 과 선발된 5개 PCR 프라이머 조합 프라이머 모두에서 음 성 반응 또는 래더링 등 비 특이적 반응이 나타나 nested PCR 반응을 수행하였다. 그 결과 PCR 조합 \#12, \#22, \#32 및 \#41을 이용한 nested $\mathrm{PCR}$ 의 경우 특정 시료에서 양성 으로 추정되는 크기의 밴드가 형성되었으나 비 특이적 밴드가 많이 나타났다. 반면 \#47의 경우 nested PCR 결과 20 개 중 10 개 시료( $1,4,6,7,9,10,14,15,16$ 및 20번)에서 특이 밴드가 형성되었고 비 특이적 반응이 나타나지 않아 $\mathrm{HuEAdV}-41$ 을 검출하는데 최적의 조합으로 분석되었다 (Fig. 3). 1차 PCR과 nested PCR 프라이머의 염기서열은 Table 3 과 같다.

\section{고 찰}

특정 미생물의 특이적 핵산을 검출하는 방법은 conventional PCR, multiplex-PCR, real-time quantitative PCR (RT-qPCR), 등온증폭(loop-mediated isothermal amplification; LAMP) 방법 등이 보고되고 있다(Kim et al., 2004; Wang et 
Table 2. Comparision of reference primer sets for the detection of HEAdV-41

\begin{tabular}{|c|c|c|c|c|c|c|c|c|}
\hline \multicolumn{3}{|c|}{ Reference primer set } & \multirow{2}{*}{$\begin{array}{l}\text { Product size } \\
\text { (bp) }\end{array}$} & \multirow{2}{*}{$\begin{array}{l}\text { Sensitivity } \\
\text { (copies) }\end{array}$} & \multirow{2}{*}{$\begin{array}{l}\text { NEAdV } \\
\text { reaction }\end{array}$} & \multirow{2}{*}{$\begin{array}{c}\text { Non-specific } \\
\text { band }\end{array}$} & \multirow{2}{*}{$\begin{array}{l}\text { Time } \\
(\min )\end{array}$} & \multirow{2}{*}{ Reference } \\
\hline \# & PCR t & & & & & & & \\
\hline \multirow{2}{*}{01} & \multirow{2}{*}{ PCR } & F & \multirow{2}{*}{482} & \multirow{2}{*}{100} & \multirow{2}{*}{+} & \multirow[t]{2}{*}{-} & \multirow{2}{*}{78} & \multirow{2}{*}[10,11]{} \\
\hline & & $\mathrm{R}$ & & & & & & \\
\hline \multirow{2}{*}{02} & \multirow{2}{*}{ PCR } & $\mathrm{F}$ & \multirow{2}{*}{260} & \multirow{2}{*}{25} & \multirow[b]{2}{*}{-} & \multirow{2}{*}{-} & \multirow[b]{2}{*}{184} & \multirow{2}{*}[12]{} \\
\hline & & $\mathrm{R}$ & & & & & & \\
\hline \multirow{4}{*}{03} & PCR & $\mathrm{F}$ & 301 & 50 & + & - & 78 & \\
\hline & & & & & & & & {$[12,13]$} \\
\hline & Nested PCR & $\mathrm{NF}$ & 171 & 25 & + & - & 78 & \\
\hline & & NR & & & & & & \\
\hline & PCR & $\mathrm{F}$ & 300 & 100 & - & - & 71 & \\
\hline 04 & ren & $\mathrm{R}$ & 500 & 100 & & & 11 & \\
\hline 04 & Nested PCR & NF & 142 & 50 & + & - & 71 & \\
\hline & Nested ren & NR & 142 & 50 & + & - & 11 & [13] \\
\hline & $\mathrm{PCR}$ & $\mathrm{F}$ & 301 & $>100$ & - & & & [10] \\
\hline 05 & PCR & $\mathrm{R}$ & 301 & $>100$ & - & - & 56 & \\
\hline J & Nested PCR & NF & 120 & 50 & - & + & 71 & \\
\hline & Nested PCK & NR & 120 & 50 & 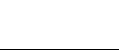 & $T$ & 11 & \\
\hline & PCR & $\mathrm{F}$ & 371 & $>100$ & + & - & 157 & \\
\hline 06 & & $\mathrm{R}$ & $5 / 1$ & -100 & & & t & \\
\hline 80 & Nested PCR & NF & 172 & $>100$ & + & + & 122 & \\
\hline & & NR & & -100 & & & & [14] \\
\hline & PCR & $\mathrm{F}$ & 306 & 50 & + & - & 157 & \\
\hline 07 & 10 & $\mathrm{R}$ & 300 & 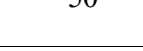 & 1 & 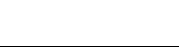 & (1) & \\
\hline & Nested PCR & NF & 132 & 5 & + & - & 122 & \\
\hline & Nested PCK & NR & 132 & 5 & $T$ & 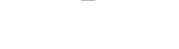 & 122 & \\
\hline & & $\mathrm{F}$ & & & & & & \\
\hline 08 & PCR & $\mathrm{R}$ & $4 / 5$ & $>100$ & - & - & 90 & \\
\hline 00 & Nested PCR & NF & 256 & $>100$ & - & - & 170 & [IJ] \\
\hline & 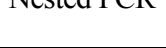 & NR & 200 & -100 & & & 170 & \\
\hline & PCR & $\mathrm{F}$ & 482 & $>100$ & _- & _- & 88 & \\
\hline 00 & PCK & $\mathrm{R}$ & 402 & -100 & 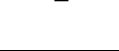 & 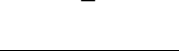 & 80 & {$\left[\begin{array}{lll}16 & 181\end{array}\right.$} \\
\hline (1) & Nected PCP & NF & & & & & & ] \\
\hline & Nested PCK & NR & 464 & 100 & - & - & 88 & \\
\hline & PCR & $\mathrm{F}$ & 300 & 100 & + & - & 100 & \\
\hline 10 & 1 & $\mathrm{R}$ & 500 & 100 & 1 & & 100 & [10_0] \\
\hline 10 & Nested PCR & $\mathrm{NF}$ & 220 & 50 & + & _ & 100 & {$[17-20]$} \\
\hline & Nested PCK & NR & $2 \angle 0$ & 50 & + & - & 100 & \\
\hline 11 & PCR & $\mathrm{F}$ & 401 & 100 & - & - & 116 & \\
\hline & & $\mathrm{R}$ & & & & & & [21] \\
\hline 12 & PCR & F & 401 & 100 & - & - & 116 & \\
\hline 12 & ICn & $\mathrm{R}$ & 401 & 100 & & & 110 & \\
\hline
\end{tabular}


Table 2. Comparision of reference primer sets for the detection of HEAdV-41 (Continued)

\begin{tabular}{|c|c|c|c|c|c|c|c|c|}
\hline \multicolumn{3}{|c|}{ Reference primer set } & \multirow{2}{*}{$\begin{array}{l}\text { Product size } \\
\text { (bp) }\end{array}$} & \multirow{2}{*}{$\begin{array}{l}\text { Sensitivity } \\
\text { (copies) }\end{array}$} & \multirow{2}{*}{$\begin{array}{l}\text { NEAdV } \\
\text { reaction }\end{array}$} & \multirow{2}{*}{$\begin{array}{c}\text { Non-specific } \\
\text { band }\end{array}$} & \multirow{2}{*}{$\begin{array}{l}\text { Time } \\
(\mathrm{min})\end{array}$} & \multirow{2}{*}{ Reference } \\
\hline \# & PCR t & & & & & & & \\
\hline \multirow{4}{*}{13} & PCR & $\mathrm{F}$ & 308 & 50 & + & - & 154 & \multirow{4}{*}[13,22]{} \\
\hline & & $\mathrm{R}$ & & & & & & \\
\hline & \multirow{2}{*}{ Nested PCR } & $\mathrm{NF}$ & \multirow{2}{*}{139} & \multirow{2}{*}{25} & \multirow{2}{*}{+} & \multirow{2}{*}{-} & \multirow{2}{*}{154} & \\
\hline & & NR & & & & & & \\
\hline \multirow{2}{*}{14} & \multirow{2}{*}{ PCR } & $\mathrm{F}$ & \multirow{2}{*}{482} & \multirow{2}{*}{100} & \multirow{2}{*}{-} & \multirow{2}{*}{-} & \multirow{2}{*}{123} & \multirow{4}{*}[23]{} \\
\hline & & $\mathrm{R}$ & & & & & & \\
\hline \multirow{2}{*}{15} & \multirow{2}{*}{ PCR } & $\mathrm{F}$ & \multirow{2}{*}{541} & \multirow{2}{*}{100} & \multirow{2}{*}{-} & \multirow{2}{*}{-} & \multirow{2}{*}{123} & \\
\hline & & $\mathrm{R}$ & & & & & & \\
\hline \multirow{2}{*}{16} & \multirow{2}{*}{ PCR } & $\mathrm{F}$ & \multirow{2}{*}{241} & \multirow{2}{*}{25} & \multirow{2}{*}{+} & \multirow{2}{*}{-} & \multirow{2}{*}{137} & {$[24]$} \\
\hline & & $\mathrm{R}$ & & & & & & [24] \\
\hline & PCR & F & 329 & 100 & - & - & 80 & \\
\hline 17 & & $\mathrm{R}$ & & & & & & {$[25]$} \\
\hline & Nested PCR & $\mathrm{NF}$ & 253 & 25 & + & - & 72 & \\
\hline & Rested TCK & NR & & $2 J$ & 1 & & 12 & \\
\hline
\end{tabular}

${ }^{*} \mathrm{~F}$, forward primer; $\mathrm{R}$, reverse primer; $\mathrm{NF}$, nested PCR forward primer; NR, nested PCR reverse primer.

Table 3. Information of finally selective PCR and nested PCR primer set for the detection of HEAdV-41

\begin{tabular}{lllcc}
\hline \hline PCR type & Primer & \multicolumn{1}{c}{ Sequence $\left(5^{\prime} \rightarrow 3^{\prime}\right)$} & Mer (nt) & Amplicon size (bp) \\
\hline \multirow{2}{*}{ PCR } & HEAdV-41_F90 & TAC TTG GAT GGT ACC TTT TAC C & 22 & 631 \\
& HEAdV-41_R10 & AAA GAA GTG TGG GCT CAT & 18 & 22 \\
\multirow{2}{*}{ Nested PCR } & HEAdV-41_F90 & TAC TTG GAT GGT ACC TTT TAC C & 22 & 434 \\
& HEAdV-41_R20 & ATA AGG GGG TAA GGG TAG TTA G & 22 & \\
\hline
\end{tabular}

al., 2007; Kim et al., 2008; Munkhdelger et al., 2013). 이 중 $\mathrm{LAMP}$ 는 특이도 및 검출 민감도가 높고 동일한 온도에서 다수의 시료를 반응할 수 있는 등의 장점이 있으나, 반면 위 양성 등 비 특이적 반응이 상대적으로 많이 나타나며 단가가 높은 단점이 있다. RT-qPCR 중 특히 Taq-man probe 방법은 특이도와 검출 민감도가 높고 신속한 방법으로 활용성이 높은 편이지만, 염기서열 분석이 어렵고 conventional PCR에 비해 활용할 수 있는 검사자가 적다. 이 와 같이 다양한 $\mathrm{PCR}$ 의 검사기법에는 고유의 방법에 따른 장단점이 존재하기 때문에 이번 연구의 대상인 HuEAdV41 의 검출방법은 conventional PCR을 선정하였다. Conventional PCR의 경우 오랜 기간 동안 많은 연구자들에 의해 안정성이 검증되었고, 필요할 경우 염기서열 분석이 가능하며, 상대적으로 쉽게 분석할 수 있어 표준 검사법
으로 적합하다고 보고(Park et al., 2016)되고 있는 등 우수 한 검사기법으로 인정받아 왔다. 이번 연구에서 개발한 HuEAdV-41 검출용 conventional PCR 프라이머 조합은 기 존의 HuEAdV-41 검출용 조건들에 비해 동등 이상의 특 이도를 보였으며 반응시간은 약 50 분 단축할 수 있는 것 으로 나타났다. 뿐만 아니라 nested PCR 반응의 경우, 약 25 배 정도의 검출 민감도를 향상시킬 수 있었다. 그러나 다양한 시료에 적용할 경우 시료 내 존재하는 방해물질 등으로 인해 특이도 및 검출 민감도에 변화가 있을 수도 있으므로 다양한 시료에 대한 추가적 시험의 필요성이 대 두된다.

한편, HuEAdV-41은 임상, 식품, 어패류, 환경 등의 시료 에서 주로 분석되고 있다. 현재까지는 시료별, 검사부처별, 연구자 및 검사자에 따라 달리 PCR 방법을 활용되고 있 


\section{Sample number}

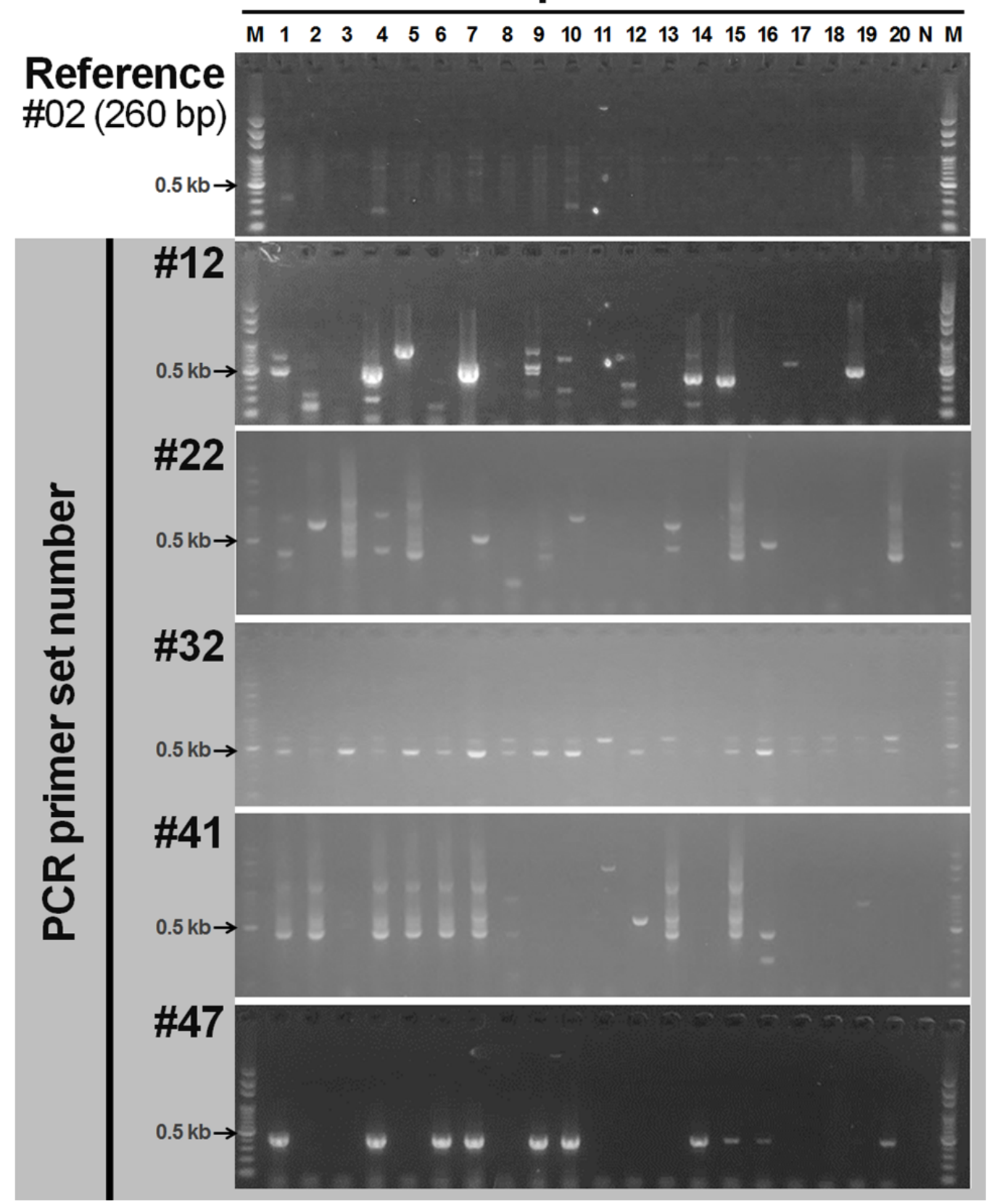

Fig. 3. Environmental sample test of six specific PCR primer sets for the detection of HEAdV-41. Lane M, 100 bp Ladder marker; lane number, sample number (1 20); N, negative control.

으나, 서로 다른 프라이머, 조건, 조성 등을 사용하고 있다. 이로 인하여 각 시료에서 검출되고 있는 핵산 단편에 대 한 비교 연구가 어렵고, 임상, 식품, 환경 등 시료를 동시 에 다루는 보건환경연구기관에서 실무를 담당하는 검사자 들 간에 불편함이 발생할 수 있다. 따라서 국내에서도 이
러한 문제를 해결하고자 질병관리본부, 식품의약품안전처, 국립환경과학원, 국립수산과학원, 국립농업과학원, 시· 도 보건환경연구원 등 관련 부처에서 수인성식품매개바이러 스 연구협의체를 구축하여 표준화된 conventional PCR 방 법을 활용한 노로바이러스 검사, 유전형 분석 등의 분석 
방법을 통합하기 위한 노력이 진행되고 있다. 노로바이러 스 외 HuEAdV-41 등 다른 수인성 식품매개 바이러스 역 시 이러한 과정이 필요할 것으로 전망되며, 검사법 개발 에서도 고려되어야 할 것으로 보인다. 아울러 효율적인 검출을 위하여 감염 또는 오염 시 상대적 고농도로 나타 나는 임상, 식품, 어패류 등의 시료는 물론 지하수 등 비 소독수와 같이 상대적으로 미량 오염이 예상되는 시료에 서도 검출이 가능한 특이도와 민감도를 갖춘 증진된 $\mathrm{PCR}$ 기법이 필요한 것이 현실이다.

따라서 본 연구에서 개발한 1차 PCR 프라이머 조합은 $631 \mathrm{bp}$ 크기로 증폭되며 약 112분의 PCR 반응시간이 필 요하여, 고농도 오염 시료인 임상, 식품, 어패류 등의 시 료에서 $\mathrm{HuEAdV}-41$ 을 검출할 경우 핵산 추출 후 1 차 PCR 수준만으로도 뛰어난 검출 민감도에 의해 HuEAdV-41를 충분히 검출할 수 있을 것으로 보인다. 아울러 환경부 국 립환경과학원의 지하수 중 노로바이러스 오염실태조사 연 구 등에 따르면 오염이 예상된 지하수 시료에서도 노로바 이러스 특이적 핵산 단편은 대부분 nested PCR 과정에 의 하여 검출되므로 지하수 등과 같은 미량 오염 시료의 경 우 nested PCR을 활용한 추가 분석이 필요하다고 사료된 다. 본 연구를 통하여 개발된 nested PCR 프라이머의 경 우 지하수 등 비 소독수에 대한 1차 PCR 반응 후 반응산 물을 주형으로 nested PCR을 추가로 수행하면 양성 시료 의 경우 $434 \mathrm{bp}$ 크기의 HuEAdV-41 핵산 단편이 검출되며, 약 112 분의 반응시간이 필요하다. 따라서 이번 연구는 향 후 임상, 식품, 어패류, 환경 등 여러 시료에서 $\mathrm{HuEAdV-}$ 41을 효율적으로 검출할 수 있는 방법으로 사용될 수 있 을 것으로 기대되며 현재 진행 중인 범 부처 간의 PCR 및 nested PCR의 표준화에 대한 기초자료로 활용될 수 있 을 것이라 사료된다.

\section{ACKNOWLEDGEMENT}

본 논문은 2018년도 신한대학교 학술연구비 지원으로 연구되었음.

\section{CONFLICT OF INTEREST}

The authors declare no conflicts of interest.

\section{REFERENCES}

Akalu A, Seidel W, Liebermann H, Bauer U, Dohner L. Rapid identification of subgenera of human Adenovirus by serological and PCR assays. J Virol Methods. 1998. 71: 187-196.

Allard A, Albinsson B, Wadell G. Rapid typing of human Adenoviruses by a general PCR combined with restriction endonuclease analysis. J Clin Microbiol. 2001. 39: 498-505.

Allard A, Albinsson B, Wadell G. Detection of Adenoviruses in stools from healthy persons and patients with diarrhea by twostep polymerase chain reaction. J Med Virol. 1992. 37: 149-157.

Arcangeletti MC, Germini D, Martorana D, Rodighiero I, Conto FD, Medici MC, Chezzi C, Calderaro A. High frequency of cultivable human subgroup $\mathrm{F}$ Adenoviruses in stool samples from a paediatric population admitted to hospital with acute gastroenteritis. J Med Virol. 2014. 63: 812-818.

Castignolles N, Petit F, Mendel I, Simon L, Cattolico L, BuffetJanvresse C. Detection of Adenovirus in the waters of the seine river estuary by nested-PCR. Mol Cell Probes. 1998. 12: 175 -180 .

Echavarría M, Forman M, Ticehurst J, Dumler JS, Charache P. PCR method for detection of Adenovirus in urine of healthy and human immunodeficiency virus-infected individuals. J Clin Microbiol. 1998. 36: 3323-3326.

Flomenberg P, Piaskowski V, Truitt RL, Casper JT. Characterization of human proliferative $\mathrm{T}$ cell responses to Adenovirus. J Infect Dis. 1995. 171: 1090-1096.

Grimwood K, Carzino R, Barnes GL, Bishop RF. Patients with enteric Adenovirus gastroenteritis admitted to an australian pediatric teaching hospital from 1981 to 1992. J Clin Microbiol. 1995. 33: 131-136.

Girones G, Puig M, Allard A, Lucena F, Wadell G, Jofre J. Detection of Adenovirus and enterovirus by PCR amplification in polluted waters. Wal Sci Tech. 1995. 31: 351-357.

Hall TA. BioEdit: a user-friendly biological sequence alignment editor and analysis program for windows 95/98/NT. Nucleic Acids Symp Ser. 1999. 41: 95-98.

Hansman GS, Oka T, Li TC, Nishio O, Noda M, Takeda N. Detection of human enteric viruses in Japanese clams. J Food Prot. 2008. 71: 1689-1695.

Jang J, Lee YJ, Kim JS, Chung JY, Chang S, Lee K, Choe BH, Hong SJ, Song JS, Park KY. Epidemiological correlation between fecal Adenovirus subgroups and pediatric intussusception in Korea. J Korean Med Sci. 2017. 32: 1647-1656.

Johansson ME, Uhnoo IMD, Svensson L, Pettersson CA, Wadell G. Enzyme-linked immunosorbent assay for detection of enteric Adenovirus 41. J Med Virol. 1985. 17: 19-27.

Jo YK, Lee CY. Detection of Salmonella typhi by loop-mediated 
isothermal amplification assay. J Exp Biomed Sci. 2008. 14: 115-118.

Kidd AH, Jonsson M, Garwicz D, Kajon AE, Wermenbol AG, Verweij MW, Jong JC. Rapid subgenus identification of human Adenovirus isolates by a general PCR. J Clin Microbiol. 1996. 34: 622-627.

Kibbe WA. OligoCalc: an online oligonucleotide properties calculator. Nucleic Acids Res. 2007. 35: 43-46.

Kim YS, Kim JB, Eom YB. Detection of pathogenic Yersinia enterocolitica strains by a rapid and specific multiplex PCR assay. J Exp Biomed Sci. 2004. 10: 333-339.

Korea Ministry of Food and Drug Safety. The statistics for reported foodborne outbreaks in Korea. 2013. Available at: http:// www.KMFDS.go.kr/e-stat/index.do, accessed Jun 30, 2018.

Kuo DH, Simmons F, Xagoraraki I. A new set of PCR assays for the identification of multiple human Adenovirus species in environmental samples. J Appl Microbiol. 2009. 107: 1219 $-1229$.

Munkhdelger J, Mia-Jan K, Lee D, Park S, Kim S, Choi Y, Wang HY, Jeon BY, Lee H, Park KH. Performance of quantitative real-time PCR for detection of tuberculosis in Granulomatous Lymphadenitis using formalin-fixed paraffin-embedded tissue. J Exp Biomed Sci. 2013. 19: 153-157.

Oh DY, Gaedicke G, Schreier E. Viral agents of acute gastroenteritis in German children: prevalence and molecular diversity. J Med
Virol. 2003. 71: 82-93.

Rowe WP, Huebner RJ, Gilmore LK, Parrott RH, Ward TG. Isolation of a cytopathogenic agent from human Adenoids undergoing spontaneous degeneration in tissue culture. Proc Soc Exp Biol Med. 1953. 84: 570-573.

Tai YF. The study of molecular biology method for the gastroenteritis syndrome in stool. National Digital Library of Theses and Dissertations in Taiwan. 2008. Masters dissertation.

Uhnoo I, Wadell G, Svensson L, Johansson ME. Importance of enteric Adenoviruses 40 and 41 in acute gastroenteritis in infants and young children. J Clin Microbiol. 1984. 20: 365-372.

Wang HY, Whang JH, Kim JP, Cho JE, Bang H, Lee H, Cho SN. Improved detection of Mycobacterium leprae by one-tube nested polymerase chain reaction. J Exp Biomed Sci. 2017. 16: 319-324.

$\mathrm{Xu}$ W, Mcdonough MC, Erdman DD. Species-specific identification of human Adenoviruses by a multiplex PCR assay. J Clin Microbiol. 2000. 38: 4114-4120.

https://doi.org/10.15616/BSL.2018.24.3.230

Cite this article as: Cho KB. Construction of Improved PCR Primer Set for the Detection of Human Enteric Adenovirus 41. Biomedical Science Letters. 2018. 24: 230-238. 